\title{
LUCES Y SOMBRAS EN EL SIGLO $X$. GERBERTO DE AURILLAC. AÑO MIL
}

\author{
Mariano Brasa Díez \\ Universidad Autónoma de Madrid
}

\begin{abstract}
RESUMEN
El recorrido de algunos momentos de la biografía de Gerberto de Aurillac nos muestra claramente al hombre que supo hermanar el pensamiento y la acción; el bien vivir con el bien decir; el trivium con el quadrivium; la enseñanza y la política; lo divino y lo humano. Estudiante de gramática en el monasterio de Aurillac y de matemáticas en la Marca Hispánica con el obispo Altón, como maestro, tenemos que asociarlo también a los emperadores Otón II y, sobre todo a Ottón III. En el filósofo de la disputa con Otrico tenemos que ver también al teólogo del De corpore et Sanguine Domini.
\end{abstract}

Palabras clave: Gerberto de Aurillac, Marca Hispánica, monje, escolástico, matemático, reformador, trivium, quadrivium.

\begin{abstract}
Going through Gerbert's of Aurillac biography we discover fairly the man who joined the mind and the action; the good life and the good say; the trivium and the qudrivium; the teaching and the politic; the divine and the human. Gramatic's scholar in Aurillac and Mathemathic's in the Hispanic Mark with the bishop Atton as his teacher, we have to associate alsso to Otto II, and especially to Otto III his tutors and friend. In the philosophic of the controversy with Otricus we have to see also the theologian of the De Corpore te Sanguine Domini.
\end{abstract}

Key words: Gerbert of Aurillac, Hispanic Mark, monk, scholar, mathemathic, reformer, trivium, quadrivium.

\section{INTRODUCCIÓN}

La filosofía se remite en los primeros siglos medievales al esfuerzo del pensamiento cumplido por el hombre occidental para comprender, entender y analizar su mundo, que no se agota en su entorno o en su contorno físico, sino que, y más principalmente, dice referencia al sentido que ese mundo ha adquirido desde la palabra divina y por la palabra divina.

Como siempre acontece en la formación de una cultura, el pensamiento filosófico en este comienzo aparece entretejido con los mimbres de los elementos culturales nacientes y condicionado, como todos, por el desarrollo político-social. Elementos y desarrollo que obedecen a ideales propuestos como metas de la cultura y que, a su vez, especifican y matizan la cultura en formación

Entre los hombres que forjaron estos ideales descubrimos las posturas auténticas y originales: aquellos que como Agustín, Beda o Gregorio Magno, aspiraban a tener hombres sabios en la Iglesia; 
o aquellos que como Carlomagno o los Otones querían políticos hábiles en sus palacios y hombres cultos en sus cortes, Alcuino, Gerberto de Aurillac; o finalmente, aquellos que podemos llamar fundadores, creadores y mantenedores de los cenobios que deseaban hombres sabios para Dios. Cuando uno se para a pensar en el quehacer del filósofo medieval, tienes que concluir que su afán por el estudio es la búsqueda denodada de una luz que, aún a riesgo de desgarrarle los ojos, le permita ver, le permita comprender y explicar su singular situación en el mundo. La "lectio" o la "disputatio" teológicas se mezclan con el deseo de conocer las disciplinas clásicas y su intento de dominar la Gramática y la Dialéctica...que, en su afán de comprensión le llevan, en algunos casos, a salirse de lo usualmente creído, a rozar el peligro... ¿Qué decir de las Matemáticas..., y de las ciencias de los paganos?

Pero el hombre siempre procede así, siempre desea salir de la oscuridad; y el hombre medieval también, por eso siempre buscó una luz que le orientara, que le guiara, que le llevara a alguna parte... La encuentra en la tradición y, aunque no fue la luz más adecuada a sus designios, necesitaba traducir a cristiano lo que la tradición le ofrecía con caracteres modélicos. Y no debemos pensar que le liberó de esta obligación el pensamiento patrístico. Es verdad que le ayudó, pero no lo suficiente. El trabajo continuó y lã luz iba haciéndose más clara y las posibilidades aumentaban, pero de cuando en cuando aparecía en medio del camino y en un contexto socio-económico o político e incluso intelectual, un determinado túnel, con nombre propio, que no dejaba ver la luz de la otra parte. Era demasiado largo, tenía demasiadas curvas. Ambivalente sería el calificativo más adecuado para definir la época en la que vamos a movernos: luces y sombras se entremezclan formando un contraste y, a medida que van pasando los años, la luz termina progresivamente imponiéndose.

Todo ese esfuerzo terminó por crear unos productos residuales que, a fuerza de haber sido enriquecidos, pudieron ser separados de lo que motivó su adquisición. La Gramática, la Retórica y la Dialéctica, las Matemáticas... que si en un momento determinado fueron sólo medios que permitieron y ayudaron a la comprensión de la doctrina sagrada, alcanzan ahora ya una dignidad indudable por sí mismas. La Dialéctica comenzó a abrirse camino y a independizarse y fue la primera en luchar por sus fueros y la que hizo levantar voces para tratar de frenar su impulso: el vae illis!, podía oírse desde cualquier púlpito, haciendo referencia a los llamados dialécticos. Progreso y modernidad van íntimamente unidos y tanto el concepto de progreso como el de modernidad fueron patrimonio de los filósofos. En el siglo XI la logica nova sustituye a la logica vetus y se creó el concepto de nuevos doctores frente a la de doctores antiguos, es decir, los que comenzaron a enseñar la Dialéctica "in voce" frente a los que enseñaban la Dialéctica "in re", que también supuso un criterio de progreso, a pesar de las críticas nacidas de la reacción teológica.

\section{CONTEXTO HISTÓRICO}

La Edad Media vivió inicialmente una contemporaneidad de la cultura, regida por una gerontocracia que hizo difícil la posibilidad de progreso. De aquí que, cuando aparece en algún campo, la idea de lo moderno, sea importante destacarla; pienso en las matemáticas y en las ciencias de Gerberto.'

1 Cfr. Maravall, J. A., Antiguos y modernos. La idea de progreso en el desarrollo inicial de una sociedad, Madrid, Ed. Sociedad de Estudios y Publicaciones, 1966, , pp. 119ss. 
Esta contemporaneidad no fue sólo un tradicionalismo a ultranza, sino algo mucho más profundo, una desconfianza en lo inmediato, en lo de hoy e, incluso, en las posibilidades del hombre que vive el hoy. "La Edad Media, muy especialmente en sus primeros siglos, vive una especie de contemporaneidad de todo cuanto ha sido y de todo cuanto es. La conciencia histórica, que tan franco arranque había tenido en el cristianismo primitivo, madura lentamente en los siglos medievales y es, naturalmente, incapaz de vender en los primeros tiempos esa intemporal conciencia de contemporaneidad. De ahí esa tendencia, tantas veces señalada, a implicar a los pasados en cada presente, a aproximarlos, a convertirlos en personajes del tiempo... Entre los diferentes pueblos, entre los distintos sabios y héroes no es advertida una separación tajante de épocas. Naturalmente unas mueren y otras nacen después, pero ésta es una pura condición biológica que no corta el hilo del saber, uno y el mismo en todo momento. Como nosotros podemos hablar hoy, considerándolo como representativo de nuestro tiempo, de un escritor que acaba de desaparecer, para el pensar tradicional de la Edad Media todos los pensadores se encuentran en ese caso, quedan bajo la ley de contemporaneidad del saber".'

Si tenemos que creer a los historiadores, el Renacimiento carolingio no pudo sobrevivir a la ruina del impèrio creado por Carlomagno. El siglo $X$ es, para Occidente, un periodo de mediocridad; mejor todavía, es un periodo de esterilidad intelectual, pero me resisto a utilizar los calificativos que utiliza Baronio para definir esta etapa de la historia. Parece como si de pronto, las luces que aquí y allá fueron encendiéndose a lo largo del siglo IX, se apagaran ahora con el comienzo del nuevo siglo. Como si de pronto un viento inesperado borrara las teorías de Scoto Eriúgena sobre la naturaleza y sobre el ser...; como si Retrammio de Corbie y su doctrina de los universales hubiera desaparecido...

Si tratamos de explicar esta regresión, tendremos que remitirnos a la desorganización política de Occidente. El Imperio carolingio ya no existe; la deposición del incapaz Carlos el Gordo en 887 simboliza el fin de un bello sueño unitario. Occidente está desmembrado, la Iglesia romana que había tratado de salvaguardar esta unidad, sufrió la consecuencia del hundimiento del Imperio. Después del asesinato de Juan VIII en 882 el papado cae en manos de la aristocracia romana hasta mediados del siglo $\mathrm{X}$ que es asumido por los emperadores germanos. Occidente va desmembrándose en reinos y los reinos en principados. En Francia grandes principados como el de Aquitania, Bourgogne... y Normandía a partir de 911, se fortifican y viven al margen del reino. En Alemania los duques de Baviera, Sajonia, Sauvia, Lorena... son quasi-independientes hasta casi el 930. Italia está dividida en muchos poderes. Las invasiones húngaras por el norte y árabes por el sur siembran el terror durante más de medio siglo.

Sin embargo los historiadores también han señalado que durante el siglo $\mathrm{X}$ y el comienzo del XI, Europa occidental se reconstruía a partir de la herencia carolingia, Otón III y Gerberto de Aurillac serían algo así como el Carlomagno y el Alcuino de la época. La ruina del poder central no significa inevitablemente anarquía, y la formación de principados permite el reagrupamiento de fuerzas en un marco más limitado. Después de la crisis y la invasión asistimos, según algunos, a un verdadero "renacimiento" y tendríamos que hablar de los Otones, padre, hijo y nieto y del Papa Gerberto, Silvestre II. ${ }^{3}$ El historiador de la cultura intelectual debe, a su vez, preguntarse sobre la vida de los centros de estudio tal y como los testimonios nos los hacen conocer.

\section{Ibidem, p. 203}

3 López, R. S., "Still another Renaissance", en American Historical Reviews, LVII (1951), pp. 1-21; Riché, P., "La Renaissance intellectuelle du Xe. siècle en Occident", en Cahiers d'Histoire, XXI (1976), pp. $27-42$. 
Dentro del contexto en el que estamos moviéndonos y en el que vamos a movernos, tenemos que hablar del año Mil. La lej'enda asegura que el año Mil fue recibido con escalofriantes profecías que vaticinaban la llegada (ceñuda) del Señor (Juez) sentado sobre una inmensa nube (negra, por supuesto) mientras se agrietaba la tierra y comenzaban a desplomarse los cielos. Relatos novelados de esa época describen minuciosamente el pánico colectivo de las últimas décadas del Novecientos, el Gran Terror al año más temido de todos los tiempos; y también, el poderoso respiro de alivio de la "gens europea" al descubrir que, finalmente, el año Mil se hunde silenciosamente en la noche de San Silvestre y todo permanece en su sitio.

"Oí predicar que el Anticristo vendría al finalizar el año Mil", decía el Abad de Saint Benoît sur Loire, Abbon de Fleury y contaba en 998 que en su juventud escuchó profecías que hacían referencia el fin de los tiempos: "Contrasté estas opiniones basándome en los Evangelios, en el Apocalipsis y en el Libro de Daniel" (Liber Apologeticus, PL. 139. ). Duby en un estudio sobre el año Mil pone de manifiesto que. "una persona culta, un maestro como el Abad Abbon no comparte estos temores y, puesto que escribe en 998 , es hasta lícito pensar que si, ante la inmediata proximidad del milenio, esos temores hubieran sido realmente importantes entre el pueblo cristiano debería, para disiparlos, haber tratado de explicar y exponer con mayor intensidad sus argumentos". 4

La imaginación se echa a volar y ve a una cristiandad inmovilizada esperando el final. Todos los horrores juntos como nubes que van acumulándose y se preparan para descargar la gran tormenta, que sería la última. Todo debe confluir al finalizar el milenio cristiano en un único e inmenso miedo. Mil años y no más, habría dicho Jesús, según la tradición; después de mil años, se leía en el Apocalipsis, Satanás habrá desaparecido. ¿Qué importancia podía tener, en aquella angustiosa vigilia, el trabajo, la patria, el amor...? La multitud penitente esperaba de un momento a otro el estruendo supremo que indicaba el final... Sin embargo, también podemos imaginar, ¿por qué no?, el estupor de alegría y el grito elevado al cielo por parte de la multitud que recogida en grupos en las oscuras iglesias o en los claustros y, sin embargo, sabedoras de que el sol luciría fuera, en las calles, en el campo... El sol, fuente eterna de luz y de vida, también brillaba la mañana del año Mil.. Esa mañana del año Mil seguía siendo Papa Silvestre II, el monje de Aurillac, el scholasticus de Reims, el obispo de Rávena y antes el discípulo del Maestro Attón en la Marca Hispánica.

\section{GERBERTO DE AURILLAC}

"Gerberto ya había llegado a la adolescencia en 967 cuando Borrell, Duque de la España citerior, fue a rezar al monasterio de Aurillac. El abad le recibió muy atentamente y le preguntó si en España había hombres expertos en las artes liberales. Habiéndole respondido Borrell, enseguida, en sentido afirmativo, el abad le rogó que se llevara a alguno de sus monjes para que se instruyera en dichas artes liberales. El Duque aceptó dicho encargo y, con el consentimiento de los demás monjes, se llevó a Gerberto, que fue confiado a Attón, obispo de Vic, con el cual... etiam in mathesi (es decir, las cuatro ciencias del Quadrivium que, como decía Boecio, llevan a la sabiduría) plurimum et efficaciter studuit". 5

4 Duby, G., L'anno Mille: storia religiosa e psicologia colletiva, Torino, Einaudi, 1976, p. 153ss.

$5 \quad: . .$. a puero aliús, et grammatica edoctus est. In quo utpote adolescens cum intentus moraretur, Borrellum citerioris Hispaniae ducem orandi gratia ad idem coenobium contigit devenisse. Quia loci abbate humanissime exceptus, post 
En las últimas décadas de Novecientos, junto a los Pirineos, en esa zona de comunicación 0 pasillo cultural para el mundo islámico y cristiano que es la Marca Hispánica, va a desarrollar su vida de estudio este monje que, unos años más tarde, en la misma línea fronteriza del año Mil, alcanzará el Pontificado, Gerberto de Aurillac, futuro Silvestre II. La Marca Hispánica era el espacio cultural más importante del Occidente cristiano, y la puerta por la que entraría en Europa el pensamiento racional. Gerberto aprendió allí del gran sabio de la época y obispo de Vic, Attón, las ciencias y sobre todo las matemáticas.

El paso de Gerberto por la Marca Hispánica es algo que le quedó grabado para siempre. Hay un contacto epistolar con sus antiguos maestros y compañeros y, en la carta 24, escrita en 984 y dirigida a "Lupito Barchinonensis" (se trata de Sunifredo Llovet), le pide un libro de astrología que él mismo había traducido: "itaque librum de astrologia translatum a te mihi petenti dirige, et si quid vales in recompensationem indubitate reposce" 6 . La carta 25 se la dirige al obispo de Gerona Mirón a principios de 984 y le suplica le envíe a Reims la obra De multiplicatione et divisione numerorum, escrita por el sabio Joseph Hispano, e inmediatamente después, en otra carta, vuelve a insistir Gerberto en que le hagan llegar esta obra. ${ }^{7}$

Pero el contacto con la ciencia árabe iba a fraguar y terminaría por tejer una tela de araña en torno al monje Gerberto, y después Papa Silvestre II. Como Boecio sospechoso de practicar la magia, entre otras cosas, cayó en desgracia ante el Emperador que tanto le había encumbrado, o Juan el Gramático del que se dijo que había hecho acondicionar un sótano en su casa para poder dedicarse a la magia, o de Focio que en su juventud habría vendido su alma a un mago judío, ahora de Gerberto se dice que no podría haber sido papa y sabio eminente sin la ayuda del diablo. ${ }^{8} \mathrm{Su}$ saber era tan vasto y tan aguda su inteligencia que el común de los mortales veía en él una especie de adivino y creían que había vendido su alma al diablo a cambio de su ciencia. Las épocas siguientes le veneraron y vieron en él esa luz que iba buscando el hombre medieval y que terminó brillando en las tinieblas, incluso en las del siglo $\mathrm{X}$.

Después de su estancia en la Marca Hispánica, el Duque y el Obispo, Borrel y Attón, viajan a Roma y presentan al joven Gerberto al Papa Juan XIII que se percata de la inteligencia del joven y también de su voluntad de aprender: "...nec latuit papam adolescentis industria, simulque et discendi voluntas", 9 y añade el cronista: “... como la música y la astronomía eran totalmente ignora-

sermones quotlibet, an in artibus perfecti in Hispaniis habeantur, sciscitatur. Quod cum promptissime assereret, ei mox ab abbate persuasum est, ut suorum aliquem susciperet, secumque in artibus accendum duceret. Dux itaque non abnuens, petendi liberaliter favit ac fratrum consensu Gerbertum assumptum duxit, atque Hattoni episcopo instruendum commisit apud quem etiam in mathesi plurimum et efficaciter studuit...". Richeri S. Remigii Monachi, Historiarum libri quatuor; lib. III, nº. 43; PL. 138, 101C. Traducción de J. M. Millás Vallicrosa, Estudios sobre historia de la ciencia española, Barcelona, C.S.I.C., 1949, p. 58. (En adelante Richeri)

6 Lattin, H. P., The Letters of Gerbert, Columbia University Press, 1961, let. 24.

7 Ibidem, let. 25 .

8 "...Ipsum Hispali magicas et necromantiam didicisse, daemonem familiarem habuisse, etiam ex quo fuit pontifex ipsum consuluisse de duratione vitae suae, ab eo quo responsum tulisse quod ante moriturus non esset quam missam celebrasset in Jerusalem, et alia absurda et inepta, Benno pseudocardinalis et achismaticus auctor commentus est et scriptis mandavit. Quam fabulam in Commentarios suos retulere Sigebertus ad annum 998, quanvis de ea dubitanter loquatur...". Richeri, Silvester Papa II, PL. 139, 57.

9 Richeri, P, Historiarum libri quatuor, lib. III, PL. 138, 102, $\mathrm{n}^{\circ}$ 44: “...nec latuit papam adolescentis industria, simulque et discendi voluntas". 
das en Italia, hizo saber inmediatamente, y a través de un legado, a Otón rey de Alemania e Italia, la llegada de este joven tan admirablemente versado en las matemáticas y tan capaz de enseñarlas celosamente". 10

Pero su formación estaba coja. Gerberto sabía matemáticas y geometría y era capaz de enseñarlas..., pero le faltaba el conocimiento profundo de la dialéctica para poder enseñarla después. Estando en Roma conoce al archidiácono de Reims, Gerannus, experto en Dialéctica, pero carente de los conocimientos matemáticos que poseía Gerberto. Los dos clérigos se entendieron y se ayudaron mutuamente: el monje estudiaría la lógica y el archidiácono estudiaría el quadrivium. Gerberto tenía una especie de compromiso con el Emperador, y como Gerannus debía volverse a Reims, el monje Gerberto quiso seguir al que iba a ser su maestro de dialéctica y pide la autorización al Emperador; autorización que le concedió, no sin alguna que otra reticencia. ¿Volvería a la corte de su nieto...?

Para Gerberto la Filosofía es la verdadera comprensión de las cosas divinas y humanas, nos había dicho en su disputa con Otrico de Magdeburgo, ${ }^{11}$ pero además ve en la Filosofía una cultura a la vez moral y literaria, indispensable para el trabajo y para el reposo: "puesto que la moral y la retórica no están separadas de la filosofía, yo he unido siempre el estudio de una al estudio de la otra. Sin duda que es más importante el bien vivir que el bien decir..., pero para los que nos ocupamos de los asuntos públicos, uno y otro son necesarios". ${ }^{12}$

Con la mentalidad de un humanista, adelantándose tal vez a Juan de Salisbury, y con una mente muy positiva, el scholasticus de Reims distingue claramente el trivium del quadrivium, como la logica de la mathesis, e incluye en la lógica, como formando un todo, la gramática y la retórica. Gerberto trataba de explicar el trivium enlazando sus tres disciplinas, y haciendo de la lógica un todo desde el que consigue la unidad de las demás. En esto consistía su principal novedad. ${ }^{13}$ Lo mismo hace con la aritmética, con la geometría, con la música y con la astronomía que forman un todo con las matemáticas de las que las considera ciencias dependientes, subordinadas de las matemáticas, partes de las matemáticas, y así dice que comenzóa iniciar a sus alumnos en la Aritmética, "que es la primera parte de las matemáticas". ${ }^{14}$

\section{TRIVIUM}

Gerberto familiariza a sus alumnos con los poetas leyendo (es decir, comentando línea a línea y palabra por palabra, según la antigua tradición y el sentido que tenía la lectio y legere) sus obras. Les da las explicaciones gramaticales, el sentido de las palabras y les hace comprender el pensamiento del autor y la elocución. Recurre a los autores clásicos tradicionales, primero Virgilio, el

\footnotetext{
10 "Et quia musica et astronomia in Italia tunc penitus ignorabantur, mox papa Ottoni regi Germaniae et Italiae....". Ident.

11 "...ut pote divinarum et humanarum rerum comprehentio veritatis...", loc. cit., $\mathrm{n}^{\circ} .70$,

12 “... philosophia... utpote in eo quod divinarum et humanarum scientiam profitetur", Ibidem, PL. 138, 105B-C.

13 Cfr. Riché, P., Gerberto, El papa del año mil, Mạrid, 1990, pp. 36ss.

14 "Arithmeticam enim quae est matheseos prima, imprimis dispositis accommodavit", Richeri, Historiarum libri quatuor; Lib. II., PL. 138, 103B.
} 
"padre de Occidente" como se le llamaba entonces, y Terencio, autor que estaba de moda en el siglo X...; después vendrían Estasio, autor de un poema sobre Aquiles, Juvenal, Persio y Horacio. Entre los historiadores Richer, sólo cita a Lucano autor de la Farsalia... ${ }^{15}$ Gerberto será acusado más tarde de ser demasiado amigo de "Virgilio, Terencio y toda la tropa de la filosofía pagana".

Los maestros explicaban, leían y comentaban los poetas, pero el alumno debía aprenderlos de memoria para ser instruido "en su modo de elocución", como dice Richer. Pero esto no era algo nuevo. Ya Alcuino había dicho que era necesario leer a los autores y conocer lo que habían hecho de bueno y así poder expresarse con la misma elocuencia que ellos. La Retórica no era una mera imitación, sino el estudio de las diversas partes del discurso: exordio, narración, argumentación, refutación, peroración. Los alumnos aprendían las figuras de la Retórica, los topoi y los retenían. Ya conocemos la extraordinaria capacidad de la memoria de los alumnos medievales pero, de cuando en cuando, había que ayudarlos y Gerberto, gran pedagogo, por otra parte, tenía el sentido de lo concreto y diseñó unos cuadros con las figuras de la Retórica y lo hizo sobre hojas de pergamino que unió con cola. "Es, escribía en su carta 92, un trabajo admirable para los ignorantes y útil para los que quieren aprender y meterse en la cabeza los contenidos tan oscuros y $\tan$. fugaces de la Retórica".

Si Gerberto recurría a los clásicos para el estudio de los poetas, ahora también vuelve la mirada a las fuentes del mundo clásico y Cicerón es el elegido. Su De inventione, De oratore y la Rethorica ad Herennium con el comentario que en el siglo IV hiciera Marius Victorinus a esta obra, constituyen las fuentes de su docencia. Pero como el maestro de Reims quería poner de manifiesto los lazos que existían entre la Retórica y la Dialéctica, Gerberto "leyó también y comentó de una manera práctica, útil, (utiliter), los cuatro libros sobre las diferencias tópicas, los dos libros sobre los silogismos categóricos, los tres libros sobre los silogismos hipotéticos, el libro único que está consagrado a las definiciones y también, el libro igualmente único, que tiene por objeto las divisiones". ${ }^{16}$ Todas estas obras que cita el discípulo de Gerberto y cronista, Richer de Saint Remi de Reims, son de Boecio. No perdamos de vista la admiración que siente el monje Gerberto hacia Boecio y tampoco el conocimiento que tiene de sus obras y de su lenguaje, como tendremos ocasión de ver más adelante. Pero, de todas las maneras, lo que es digno de ser señalado es que los "silogismos categóricos" y los "silogismos hipotéticos" no fueron conocidos hasta esta época. Sabemos, por otra parte, que Abbon de Fleury, que fue a Reims a aprender la Dialéctica antes de la llegada de Gerberto y que dirigió la escuela de su abadía a partir de 975 , comentaba también estas
obras. ${ }^{17}$

Volvamos a echar mano del discípulo e historiador Richer y veremos cómo enseñaba su maestro la Dialéctica, ciencia que aprendió con el arcediano de Reims Gerannus, en un tiempo ciertamente breve: “...etiam logicae scientiam accipiens, in breve admodum profecit,..." (PL. 138, 102C). El mundo clásico entra de nuevo en escena e interpreta los mejores textos de las obras que componían la llamada logica vetus: Isagoge de Porfirio con la traducción de Marius Victorinus y el comentario de Boecio; las Categorías y el De Interpretatione de Aristóteles; los Tópicos traducidos por

\section{Cfr. Ibidem, 103A.}

16 "... Nec non et quatuor de topicis differentiis libros, de sillogismis cathegoricis duos, de ypotheticis tres, deffi-

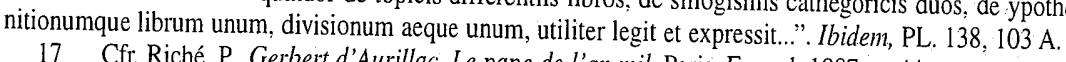

17 Cfr. Riché, P., Gerbert d'Aurillac. Le pape de l'an mil. Paris, Fayard, 1987, p. 44. 
Cicerón con los comentarios de Boecio. Si añadimos las Diferencias tópicas, los tratados Sobre los silogismos categóricos e hipotéticos, Sobre la división y las Definiciones que hemos visto en la nota, ${ }^{15}$ nos encontraremos con todos los tratados lógicos de Boecio. El estudiante tiene ante sí lo que van a ser sus herramientas de trabajo: en Las Categorías analizará los diez géneros del ser: substantia, quantitas, qualitas...; en el De Interpretatione, Perihermeneias, el estudiante se encuentra con la teoría de la proposición: si se trata de una proposición afirmativa, negativa, universal, singular... y de sus modos: posible, contingente, necesario; en la Isagoge de Porfirio o Introducción, el alumno se familiariza con las cinco voces: género, especie, diferencia, propio, accidente. Estas voces y su estudio lleva a unos a hablar de concepciones de la mente, mientras que otros quieren ver realidades sustanciales. Finalmente los Tópicos de Cicerón convertían al estudiante en un conocedor de las figuras del discurso porque tenía, además de decir bien (Gramática), saber decir (Retórica).

No acababa todo aquí. Ahora iba a comenzar lo que podemos llamar "clases prácticas". Nos dice Richer que el maestro Gerberto enviaba a sus alumnos, con este bagaje, a un "sofista" para que se ejercitaran en la discusión "porque quería que se expresasen con una maestría tal que pudiera creerse que hablaban sin la ayuda del arte, lo que constituía la suprema perfección en el orador".18 Había que aprender a "disputar", a comprometerse en las discusiones. La época de la simple lectura, de la lectio, estaba comenzando a ceder el paso a la quaestio; como la logica vetus estaba a punto de convertirse en logica nova. Y en este progresar y modernizarse las escuelas monacales iban a dejar pasar a las escuelas urbanas... . Gerberto quería que sus alumnos supieran preguntar y responder: ponere quaestiones et resolvere quaestiones; pero había que hacerlo con elegancia, con discreción y con eficacia. La enseñanza dada y recibida en Reims no terminaba en el placer de poseer una rica cultura; una buena formación y una capacitación para que el alumno desempeñara una función pública en la ciudad. No era sólo eso lo que pretendían los maestros de Reims, con Gerberto a la cabeza; estaban convencidos de que no se podía obrar bien sin poseer los medios para pensar y hablar bien. El monje de Aurillac, Gerberto, había aprendido la lección de Cicerón y de Boecio, y fue precisamente "el último de los romanos" quien se constituyó en su gran modelo. ${ }^{19}$

\section{QUADRIVIUM}

Hemos hecho alusión a la modernidad y contemporaneidad y a lo difícil que podía resultar hablar de progreso: sin embargo, decíamos que, cuando en algún campo surgía esta posibilidad y la idea de lo moderno afloraba, teníamos que destacarlo. Ha llegado el momento: siglo X. Tenemos un personaje que va a representar la modernidad, Gerberto de Aurillac, y unas ciencias, reunidas en la segunda de las ramas del programa de Alcuino y que Boecio llamó quadrivium (aritmética, geometría, música y astronomía).

El resurgir de las matemáticas que se produce en los años 970 estuvo siempre relacionado con el monje Gerberto, con el scholasticus de Reims Gerberto, con el obispo de Rávena Gerberto y hasta

18 "..Qua instructis sophistam adhibuit; apud quem in controversiis exercerentur, ac si ex arte agerent, ut praeter agere viderentur, quod oratoris maximum videtur". Richeri, Historiarum libri quatuor, Lib. III, PL. 138, 103 A-B.

19 Cfr. Riché, P., Gerbert d'Aurillac. Le pape de l'an mil. Paris, Fayard, 1987, p. 45. 
con el Papa Gerberto, Silvestre II. Sabemos de su formación literaria, conocemos sus contactos con la ciencia en la Marca Hispánica y su saber matemático, geométrico, astronómico y musical aprendido con Attón en Vic. Quiero señalar aquí tres aspectos o tres etapas que se dan en el lento caminar matemático de la época: 1) las matemáticas como novedad; 2) reacciones ante el nuevo mundo matemático y 3) un reconocimiento matemático.

\section{Las matemáticas como novedad}

Las matemáticas afectaron al siglo X, más que a los siglos anteriores, como algo nuevo. Richer, el discípulo cronista de Gerberto, escribía que "la música y la astronomía eran completamente desconocidas en Italia cuando llegó Gerberto", mientras que "la Galia no había conocido nada de música durante mucho tiempo". ${ }^{20}$ Las pretensiones de Richer encontraron eco, a pesar de lo que en su crónica pueda haber de adulación. El propio Gerberto llegó a decir que su nuevo método de cálculo era "desconocido o profundamente olvidado" hasta su época. ${ }^{21}$ Un admirador añadiría también que antes de Gerberto "ninguno de los hombres ilustrados de Italia, Galia o Alemania tenía idea de cómo cuadrar el círculo".22

Tenemos que hablar también de pruebas indirectas en cuanto a la novedad de las matemáticas se refiere, y tenemos que recurrir al sufrimiento de sus discípulos y del propio Gerberto que estudió las matemáticas en España con el obispo Attón "verdaderamente con mucha dureza". ${ }^{23}$ Sin embargo, cuando en Roma se le pregunta por sus conocimientos y sobre qué es lo que en verdad podía enseñar, el monje, recién llegado de España, confiesa una modesta habilidad en las disciplinas matemáticas: "in mathesi se satis posse" (PL. 138, 102B).

Si Gerberto nos habla de sus fatigas y también de sus éxitos matemáticos, sus discípulos sólo nos hablan de dificultades e incluso de sudores a la hora de enfrentarse con las disciplinas matemáticas. Gerannus el archidiácono de Reims que se comprometió con Gerberto a ser su maestro de lógica a cambio de ser su discípulo en matemáticas, "terminó afectado por la dificultad de las matemáticas y negado totalmente para la música". ${ }^{24} \mathrm{El}$ monje Richer cronista y contador, diez años después se secaba todavía el sudor al recordar "lo mucho que sudábamos con las matemáticas". Una vez acabada la aritmética, se aprendía lo principal de astronomía, "materia apenas inteligible", con la ayuda de modelos y más "sudor". La geometría les costaba mucho trabajo. ${ }^{25}$ El "sudor" de Richer y de sus condiscípulos pronto se convertiría en moneda de curso legal entre los cronistas del resur-

20 "Et quia musica et astronomia in Iatlia tunc penitus ignorabantur... Inde etiam musicam, multo autem Galiis ignotam". Richeri, Historiarum libri quatuor, Lib. III, PL. 138, 102 A y 103 B.

21 "... ipsa norma rationis aut neglecta aut fuditus ignorata". Bubnov, " Fragmentum de norma rationis abaci" en Gerberti... Opera Mathematica, Berlin, 1899, p. 23, líneas 13 y 14.

22 Franco de Lieja, De quadratura circuli, ed. Winterburg, Leipsig, 1882, pp. 135.190. " dubitationem... tantum ut in ea (quadratura circuli) omnes italie gallie atque germanie defecerint sapientes".

23 "Apud quem etiem in mathesi plurimum et efficaciter studuit", Richeri, Historiarum libri quatuor, Lib. III, PL. $138,101 \mathrm{C}$.

24 "G (erannus) vero, cum mathesi operam daret, artis deficultete victus, a musica reiectus est", Richeri, loc. cit., PL. 138, $102 \mathrm{C}$.

25 "Qui labor ei in mathematicis impensis sit"... "Ratio vero astronomiae quanto sudore collecta sit... Quae cum pene intellectibilis sit... In geometria vero non minor in docendo labor expensus est". Richeri, op. cit., PL. 138, 103-105, nn. $49,50,50,54$. 
gimiento, y había una especie de consuelo generalizado porque, los estudiantes que trataban de aprender las nuevas reglas de cálculo de Gerberto "apenas las comprendían". ${ }^{26}$

\section{Reacciones ante el nuevo mundo matemático de Gerberto}

Para los contemporáneo de Gerberto las matemáticas constituían un nuevo mundo. Los nuevos mundos producen dos clases de reacciones que se manifiestan como opuestas: o bien la desesperación del exilio o bien la excitación de la exploración. Ante el nuevo mundo matemático de Gerberto se produce la segunda manifestación: la excitación que produce el descubrimiento, lo nuevo, y su exploración. Esta reacción es lenta y se necesitan varias dosis de ánimo y, a veces, hasta hay que aumentar la dosis...

Cuando Richer relataba los recuerdos desagradables estaba apuntando a unos tibios sentimientos dentro de un grupo, reducido, es verdad, pero que, a pesar de los sudores, veía una luz en la lejanía, una brisa que mitigaba ese calor... ¿Estaría barruntando lo nuevo?. Gerberto era consciente del valor del conocimiento matemáticos y, en la sociedad docta, tenía tres o cuatro, llamaríamos hoy, corresponsales matemáticos, claramente asiduos: Constantino de Fleury, Adalberón de Reims, Remigio de Tréveris e incluso el hermano Adán. ${ }^{27}$ Pero, a pesar de esto, la única emoción o reacción que podemos registrar ante la nueva ciencia fue la admiración hacia el único hombre que la había dominado. La admiración fracasó también ante la sociedad docta. Las matemáticas todavía eran sospechosas. Los contemporáneos que escribieron, con lágrimas y esfuerzos, tratados sobre el cálculo (Abbón y Bernelinus) hablan de la "envidia" de personas que rechazaban sus descubrimientos. ${ }^{28}$ Gerberto y sus partidarios lucharon solos; Gerberto venía del territorio prohibido donde había aprendido las matemáticas, la utilización y ¿creación? del ábaco, "...the abacus of Gerbert is the fruit of his study in Catalonia, prior to his going to Reims", y había tenido contacto con las ciencias "demoníacas"... Cuando los tiempos cambien, las matemáticas serán el valor más importante en el "curriculum" de Gerberto; se le hará una halagadora oferta de trabajo como profesor de matemáticas; se le querrá tener cerca de la Corte por su condición de matemático, qua matemático y, cuando Gerberto aparece en Roma, el Papa escribe a Otón I comunicándole la llegada de un joven diligente y vehemente... experto en matemáticas. ${ }^{29} \mathrm{La}$ rápida respuesta del Emperador sugería al Papa que "retuviera al joven, asegurándose que de ninguna manera se le permitiera marchar" ${ }^{30}$

Estamos ante el éxito de lo nuevo, de lo moderno, del progreso... Unos años más tarde, y muerto Otón I, su nieto, Otón III escribe una carta a Gerberto pidiéndole instrucción sobre la aritmética. El erudito Emperador iba a demostrar, a parte de su gran amistad y admiración por el amigo y maestro, una notable inclinación por las matemáticas: "Nos enseñareis el libro Sobre la Aritmética, a fin

26 "Abacum... rapiens, regulas dedit, quae a sudantibus abacistas vix intelliguntur". G. de Malmesbury, De rebus gestis regum Anglorum, II, c. 167, ed. W, Stubbs, vol. I, p. 194, 14-15.

27 Crr. Murray, A., Reason and Society in the Middle Ages Oxford, Oxford University Press, 1978, p. 168; trad. cast. Razón y' sociedad en la Edad Media, Madrid, ed. Taurus, 1983, p. 180.

28 El maestro Abbo estudió música "occulte propter invidos", Fleury, Abbo de, In calcullum Victorii commentarium, ed. Bernelinus, Liber Abaci, ed. A. Olleris: "Ad hoc eccedit quorundam improbitas qui nihil recipiendum autumant nisi quod sacraverit Libitina, quique quod assequi nolunt venenose dente...lacerare non omittunt. Quos equidem existimo... invidiae livore ignota blasphemare".

29 Cfr. Richeri, Historiatum libri quatuor; Lib. III; PL. 138, 102 B: :... in mathesi se satis posse".

30 Ibidem, "...ut iuvenem retineret nullumque regrediendi editum ei ullo modo preberet". 
de que, perfectamente al corriente de las enseñanzas de este último, tengamos algún conocimiento de las sutilezas de los antiguos".31

\section{Reconocimiento matemático de la época de Gerberto}

Hasta aquí hemos estado hablando de pasado, pero en este tercer apartado quiero ver a Gerberto vinculado no con el pasado, sino con el futuro y con la Edad Media Central, porque Gerberto de Aurillac abre un período e inaugura una nueva fase en la historia de las matemáticas. Ya no estamos sólo en la "aritmética", ha llegado el momento de salir del "tiempo oscuro" y seguir el hilo de la historia para adentrarnos en una región más brillante donde se nos ofrecerá la posibilidad de una nueva conquista, de un nuevo mundo: la conquista gradual y el nuevo mundo del pensamiento occidental ilustrado mediante la aritmética y la geometría y la astronomía y la música...

Es significativo que entre los personajes más representativos de la reflexión cultural en el período que va de la mitad del siglo $\mathrm{X}$ a la mitad del siglo XI, nos encontremos con un gran maestro, Gerberto de Aurillac que deja una gran impronta en el pensamiento contemporáneo, y tres alumnos de los que hablaban de sus "sudores" y sus "lágrimas": Abbón de Fleury, Adalberón, Arzobispo de Reims, "el padre Adalberón", como le llamará Gerberto, y Fulberto de Chartres...

\section{FILOSOFÍA}

Amante del saber, conocedor del Organon aristotélico, Gerberto es consciente de que no solamente el Organon es el fermento de la organización del saber. Para los cristianos se planteaba el problema de un conocimiento de Dios, sea el Dios de la Biblia, sea el Dios de la naturaleza y, por lo tanto, el problema de una coordinación, muy diferente, sin duda, de este conocimiento con las otras disciplinas. Superponer a las siete artes, disciplinas "mundanas", "paganas", una disciplina divina; establecer como Casiodoro un díptico de las Institutiones divinarum et saecularium lectionum, no podía ser más que una solución momentánea, a la que no se resignarán jamás ni una mente activa, ni un alma religiosa preocupada por la unidad. Se planteaba un doble problema, que ya había aparecido en Alcuino y que seguiría después en el siglo XII con Hugo de San Víctor en su Didascalion: ¿cómo constituir un organismo del saber humano total, incluido Dios?; ¿cómo establecer la subordinación de las disciplinas humanas, racionales, a la ciencia divina?...

Desde hacía tiempo el conjunto del saber, abarcando ciencias humanas y ciencia divina y las siete artes como grados progresivos hacia una única sabiduría, era llamado filosofía. ${ }^{32}$ Es, en suma, sin otra precisión que tal vez su extensión, el sentido elemental, más próximo de la etimología:

31 Aurillac, G. d', Correspondence. Texte établi, traduit et coomenté par P. Riché, J. P. Callu, 2 vols. Paris, 1993, carta, 186, p. 483.

32 Alcuino, Grammatica, PL. 101, 853 C: "Faciam quod rogastis, vobisque ad videndum ostendam septem philosophie gradus". Dialectica, cap. I; ibidem, 952: "Primo omnium dic unde dicta sit philosophia?. -Ab amore sapientiae... Dic eius quoque definitionem. -Philosophia est naturarum inquisitio, rerum humanarum divinarumque cognitio, quamtum homini possible est aestimare". S. Eriúgena, De praedestinarione, c. I; PL. 122, 358 A: "Conficitur in de veram esse philosophiam veram religionem, conversique veram religionem esse veram philosophiam". Gerbertus, véase toda la disputa mantenido con Otrico sobre la división de la Filosofía en todas las ciencias, Richeri, Historiarum libri quatuor, Lib. III, nn. 55-61; PL. 138, 105-107. 
"amor a la sabiduría". Todo lo que hasta aquí hemos visto de Gerberto, incluso lo que no hemos visto, constituye su filosofía.

La fama de Gerberto se extiende por Francia e Italia. El número de sus alumnos aumentaba cada día. La fama de tan gran maestro no se limitó sólo a Francia, sino que se extendió también a los pueblos de Alemania, cruzó los Alpes y llegó hasta los mares Tirreno y Adriático. En esta época hay un maestro importante en Sajonia, Otrico de Magdeburgo que había oído las alabanzas dirigidas al maestro galo y se había dado cuenta de que Gerberto cuidaba mucho la división y la había convertido en bandera para sus argumentaciones. Este método llamó la atención de Otrico y encareció a sus amigos que le trajeran lecciones del maestro Gerberto y algunos ejemplos; pero sobre todo, ejemplos basados en la filosofía porque, pensaba Otrico, era en una división metódica de la filosofía donde podría más fácilmente apreciar la exactitud de los comportamientos de un hombre que era considerado como un gran filósofo: "...filósofo muy experto, laureado en las tres partes de la filosofía", dirá de él Otón III. Se envió a Reims a un cierto sajón: "Saxo quidam", que parecía el más idóneo para esta misión...

El sajón enviado a Reims parece que en un momento determinado, entre división y división de la filosofía, y entre géneros y especies, perdió el hilo del discurrir filosófico del maestro Gerberto. La relación entre las matemáticas y la física no terminó de verlo claro, como tampoco vio claro la relación que podía haber entre género y especie. A veces un mal entendido, o un no prestar atención a lo que se dice, se convierte en algo malévolo que sirve para descalificar a alguien. Es lo que sucedió entre Otrico y Gerberto. Según el sajón el maestro galo habría dividido mal la filosofía..."eo quod duarum aequalium specierum, alteri alteram ut generi speciem figura mentiebatur", y por lo tanto no podía construirse una buena filosofía; más, desconociendo y confundiendo lo que de divino y humano hay en la filosofía, no hay nadie que sea capaz de filosofar. ${ }^{33}$

Las acusaciones del germano preocupan a Otón II que no termina de creerse lo expuesto por Otrico, y no sale de su asombro ante los presuntos errores de Gerberto. Ante semejante situación el Emperador Otón II "llama a capítulo" a Otrico de Magdeburgo y a Gerberto de Reims. La reunión va a tener lugar en Rávena.

El cronista refiere los nombres de algunos de los asistentes y la alocución de Otón II en la que dijo: "Creo que las reflexiones y los ejercicios frecuentes hacen progresar la ciencia humana, con la condición de que los temas, elegidos convenientemente, sean tratados por todos los sabios con un lenguaje claro y adecuado...Revisemos, a partir de ya, el esquema de las partes de la fillosofía que nos fue mostrado el año pasado. Examinémoslo todos con el mayor detenimiento y cuidado posible, y que cada uno de vosotros, como expertos, diga lo que piensa, bien a favor, bien en contra. Si todo es correcto, confírmenlo con su aprobación unánime; si debe ser corregido, hágase según la opinión de los sabios, o reprobado o redactado de nuevo siguiendo las normas". 34

Esta era la situación. Otrico toma la palabra y vuelve sobre su posición inicial afirmando que Gerberto lo había expuesto de este manera, que había sido recogido y escrito por sus oyentes y que después se lo había dado a leer al Emperador. Una vez leído se lo pasó a Gerberto, qui diligenter 
eam percurrens, lo aprobó en parte, lo cuestionó en otras y declaró "simulque" que no era de esa manera como él lo había expuesto.

El Emperador le suplica que lo corrija y dice: "No ha sido la envidia de los malévolos, cuyo espíritu parece revolotear por la asamblea, lo que me movió a hacer la división de la Filosofía, sino algo que siempre estuvo muy claramente ordenado en mi mente, ...aunque esté viciada, según el parecer de algunos... Digo que las matemáticas, la física y la teología, desde siempre han pertenecido al mismo género y participan "aequaliter" de su género... Y esta es mi opinión sobre el tema. Quien tenga algo contra esta doctrina que lo exponga mediante razones y que nos lo haga entender". 35

A una señal del Emperador, Otrico volvió a decir: "Ya que trataste brevemente las partes de la filosofía, sería conveniente que dividas y expliques la división. Si esto puede hacerse y como probable división, tal vez viciada, puedas corregirla". Gerberto respondió de la siguiente manera, apelando incluso a autoridades y como queriendo dejar definitivamente claro cuál era su posición, y no la que el Saxo quidam le había contado: "...puesto que la Filosofía es la verdadera comprensión de las cosas divinas y humanas y para que no se nos tache de apatía en nuestra argumentación, como algunos de nuestros oyentes pueda pensar...", recurre a Vitrubio y a Boecio y dice: "La filosofía es un género, cuyas especies son: práctica y teórica; las especies prácticas son: dispensativa, distributiva y civil; las especies teóricas son: naturalis (física), intelligibilis (matemáticas) et intellectibilis (teología). Sub theorica vero non incongrue intelliguntur phisica naturalis, mathematica intelligibilis, ac theologia intellectibilis. Rursusque mathematicam sub phisica non praeter rationem collocamus" ${ }^{36}$ Gerberto en este texto coge de Boecio no sólo el esquema de la división de la Filosofía, sino incluso hasta su vocabulario y hay una alusión muy clara a la distinción intelligentia-intellectus (Cfr. BOECIO, In Porph., PL. 63, 11B).

Hay momentos en la vida del hombre que necesita el hombro de otra persona para apoyar la cabeza, tal vez para llorar y no ser visto... . Gerberto estaba atravesando un mal momento. Estaba en el período más delicado de su vida, tanto desde el punto de vista doctrinal, como desde el personal y político. Había tenido la discusión con Otrico donde se le había cuestionado su método y su doctrina y donde había visto segundas intenciones de malévolos y envidiosos y, sobre todo, los malos informadores; en teología defendía doctrinas un tanto sospechosas, ¿galicanismo?; y en política, sobre todo después de la muerte de Adalberón, obispo de Reims que había designado a Gerberto como su sucesor y que a partir de aquí "...mil muertes se habían preparado, porque el padre Adalberón me había designado como su sucesor con el favor del conjunto del clero.... ${ }^{37}$ Son nueve años desde la muerte de Adalberón 989 hasta su elección como obispo de Rávena en 998; su polémica elección en 991 y posterior sustitución en 995 como arzobispo de Reims; y las consecuencias del concilio de San Basilio, su enfrentamiento con el Papa Juan XV y las condenas sufridas en los concilios de Aquisgrán, Mouzon, Reims y Pavía... Demasiados acontecimientos para llevarlos una sola persona. Entre tanta oscuridad va a aparecer un rayo de luz, en forma de carta, que tiene como

35 "Nec movebit me malivolorum livor, quorum instinctu id factum est, ut rectissima philosophiae divisio probabiliter dilucideque a me nuper ordinata, unius speciei suppositione visiata sit. Dico itaque mathematicam, phisicam, et theologiam aequaevas eidem generi subesse. Earum autem genus, eis aequaliter participare. ...Et ego quidem de his ita sentio. Caeterum si quis contra haec contendat, rationem... ". Richeri, Hisrtoriarum libri quatuor; Lib. III, PL. 138, 107 AB.

36 Ibidem, $107 \mathrm{C}$.

37 Aurillac, G. d:, Correspondence, carta 152, p. 375. 
remite La Corte y que va dirigida a Gerberto. Es una carta del Emperador Otón III que le saluda de este modo: "A Gerberto el más hábil de los maestros, laureado en las tres partes de la filosofía"..., y le invita a ser su preceptor. Mayo de 997.

A Gerberto le quedan dos años para llegar al pontificado y en este tiempo está en estrecho contacto con el Emperador Otón III. Podría incluso decirse que juntos planifican el programa a desarrollar por Gerberto cuando se convierta en el Papa Silvestre II. Otón desea que Gerberto ponga al servicio del estado su gramática y su retórica, su filosofía también y..."que elimine su rudeza sajona y que despierte en él la finura griega que también corre por sus venas, porque si existe un hombre capaz de despertarla, eres tú con tu vasta ciencia, y encontrarás en nosotros la chispa del genio que anida en Grecia". ${ }^{38}$

Durante el verano de 997, maestro y discípulo, obispo y emperador, tienen ocasión de hablar sobre las matemáticas y también sobre filosofía. Gerberto hablaría al joven discípulo y amigo de la discusión que tuvo con Otrico de Magdeburgo y que presidió su padre, el Emperador Otón II en Rávena. Había llegado el momento justo para escribir su De rationali et ratione uti que el maestro Gerberto dedica al Emperador Otón III: "Domno. et glorioso Ottoni, Caesari semper Augusto Romanorum imperatori, Gerbertus episcopus, debitae servitutis obsequium". ${ }^{39}$ En el prefacio Gerberto anticipa a Otón el ideal imperial que ambos comparten. Tal vez Gerberto contribuyó a que la idea de la renovación del imperio romano (Renovatio Imperii Romanorum) calara profundamente en Otón III. ${ }^{40}$

El tema a tratar tiene, a primera vista, un carácter lógiço gramatical, pero la solución que va a dar Gerberto lo eleva a un plano metafísico. De todos es conocido el axioma de la lógica aristotélica según el cual, en un juicio el predicado tiene que ser más universal que el sujeto: mortal, predicado, es más universal que Sócrates, sujeto. Se lee en Porfirio que "lo racional utiliza la razón" y aquí no se cumple la mayor universalidad del predicado con respecto al sujeto, porque puede haber racionalidad sin uso efectivo de la razón." ${ }^{41}$ Tras una larga introducción dialéctica, Gerberto resuelve el problema recurriendo a la terminología boeciana de los tres planos del ser que ya había utilizado en su disputa con Otrico de Magdeburgo:

"Lo racional o, para hablar con más universalidad, los géneros, las especies, las diferencias, las propiedades y los accidentes... son, en los intelectibles, formas de las cosas. En los inteligibles son o pasiones o actos. Pues en el alma son pasiones, en el momento en que son pensados, ya que todo pensamiento (intellectus) es una pasión del alma. Cuando un estudio exacto y perfecto los hace pasar al estado de ciencia, son actos del alma, pues toda ciencia es un acto del alma. Por tanto, es necesario considerar a lo racional de diversas formas, según se halle en la especie sempiterna del hombre - bien en los intelectibles, o bien en los inteligibles - o en los seres naturales. Allí están las formas o los actos sempiternos, aquí la potencia que puede pasar al acto... Por tanto, ya que la diferencia racional está sustancialmente presente en Cicerón o en el hombre, y que, en cambio, el

38 Ibidem, carta 186, p. 483.

39 . Silvestri II Papae, De rationali et ratione uti, PL. 139, 159-168.

40 Cfr. Folz, R., La naissance de Saint-Empire, Paris, 1967, p. 134.

41 "Quomodo ergo 'ratione uti ' praedicatur de 'rationali', cum maius esse videatur 'rationale' quam 'ratione uti'?". Silvestri II Papae, De rationali et ratione uti, PL. 139, $160 \mathrm{~A}$. 
hecho de usar la razón está accidentalmente, está justificado decir que utilizar la razón se predica de lo racional como un accidente de su sujeto... ${ }^{42}$

Gerberto añade que utilizar la razón se sitúa en la categoría del hacer, lo que prueba por segunda vez que se trata de un accidente: "igitur Uti ratione accidens est". Hay algo que debe tenerse en cuenta y es que la proposición inicial, para que sea verdadera, debe ser considerada en sentido particular, "un racional utiliza la razón", porque si se toma universalmente sería falsa, como se ve en el planteamiento mismo del problema.

En el texto que he citado se dan una serie de influencias que deben ser señaladas porque, además de la de Boecio, también está presente San Agustín, tal vez Scoto Eriúgena y ciertamente Aristóteles con su doctrina del acto y la potencia y el pensamiento como pasión del alma.

\section{CONCLUSIÓN}

De Gerberto hemos visto su aspecto humanista, filósofo, científico. Es verdad que alguien podrá decirnos que Gerberto de Aurillac ni es humanista, ni es filósofo y mucho menos es científico. Pero el recorrido de algunos momentos de la biografía de este monje de Aurillac, del scholasticus de Reims, del obispo de Rávena, del precepter de Otón III y del Papa Silvestre II, nos ha mostrado claramente a un hombre que supo hermanar el pensamiento y la acción; el bien vivir con el bien decir; la enseñanza y la política; lo divino y lo humano... Cuando en la disputa que tuvo con Otrico en Rávena definía la filosofía como "la verdadera comprensión de las cosas divinas y humanas", parece como si estuviera pensando en su vida y viera en ella cosas divinas y humanas que tratara de comprender.

Debemos situarnos a mediados del siglo $\mathrm{X}$ y seguir los pasos de este "indigente, exiliado, a quien no sostenían linaje ni fortuna,... preferido a hombres ricos e insignes por la nobleza de su familia...", ${ }^{43}$ y le veremos estudiando la gramática en el monasterio de Aurillac, las matemáticas (aritmética, geometría, música y astronomía) en la Marca Hispánica con el maestro Attón, obispo de Vic, y la dialéctica en Reims con el archidiácono y maestro Gerannus. Le veremos disputar con Otrico sobre la división de la Filosofía, y siguiendo el curso del tiempo, también tenemos que verlo asociado a los Emperadores Otón II y Otón III.

Hay en la vida de Gerberto de Aurillac otros aspectos que no he tratado en este trabajo o lo he hecho sólo de manera tangencial; estoy refiriéndome a Gerberto desempeñando durante casi cinco años el papel de Papa con el nombre de Silvestre II, aludiendo, con este nombre, al contexto histórico semejante al que se movió en el siglo IV su homólogo Silvestre I y el Emperador Constantino. Tampoco he visto al Gerberto teólogo en su obra De Corpore et Sanguine Domini, ni me he detenido en los documentos y bulas que como Sumo Pontífice llevaban su firma. Los historiadores de la Teología y de la Iglesia se encargarán de este faceta de Gerberto de Aurillac. ¿ Y del Gerberto político?...

43 Aurillac, G. d'., Correspondence, carta 217, p. 649. 
El 12 de mayo de 1003 muere Silvestre II. En 1009 Sergio IV sucesor y buen conocedor de Gerberto, mandó poner en San Juan de Letrán una lápida que recordaba a Silvestre II con estas palabras:

"La virgen, que favorece las artes, y Roma, cabeza del mundo, le dieron fama en todo el universo... El César, Otón III, de quien fue siempre fiel y devoto servidor, le ofreció esta iglesia. Uno y otro ilustran su tiempo con el resplandor de su sabiduría; el siglo se alegra, el crimen perece... Llevaba un lustro realizando las funciones de Pedro cuando le llegó la muerte. El mundo se heló de espanto... Al pontífice Sergio, su sucesor, un tierno sentimiento de piedad le ha llevado a levantar esta tumba a su amigo".

Este epitafio era el comienzo de una leyenda. ${ }^{44}$

Mariano Brasa Díez

Departamo de Filosofía

Universidad Autónoma de Madrid

MADRID

44 Aldoni. M., "Gerberto e la sua storia", en Studi Medievali, 18/2 (1977), pp. 629-704; vol. $21 / 2$ (1980), pp. 493 622; vol. 24 (1983), pp. 167-242. El epitafio se encuentra en la página 630. 